\title{
THE BINDER SYNDROME: REVIEW OF THE LITERATURE AND CASE REPORT
}

\author{
Nedev P. \\ Department of Neurosurgery, Othorhinolaryngology and Ophthalmology - Medical University \\ Varna; Clinic of Otorhinolaringology - University Hospital "Saint Marina" -Varna \\ Reviewed by: Assoc. Prof. D. Marev, MD, PhD
}

\begin{abstract}
Binder syndrome or maxillo-nasal dysplasia (nasomaxillary hypoplasia) is an uncommon developmental anomaly affecting primarily the anterior part of the maxilla and nasal complex. A 4-year-old boy with maxillo-nasal dysplasia (Binder's syndrome), featuring maxillary hypoplasia and relative mandibular prognathism, combined with acute leucosis. We review the literature and describe how 3-dimensional CT scanning was used to evaluate the facial morphology. The principal features, diagnosis and management of the syndrome are discussed.
\end{abstract}

Keywords: Binder syndrome, maxillo-nasal dysplasia, nasomaxillary hypoplasia

\section{INTRODUCTION}

The essential features of maxillo-nasal dysplasia were initially described by Noyes in 1939(1) although it was Binder in 1962 (2), who first defined it as a distinct clinical syndrome. He reported on three cases and recorded six specific characteristics - arhinoid face, abnormal position of nasal bones, inter-maxillary hypoplasia with associated malocclusion, reduced or absent anterior nasal spine, atrophy of nasal mucosa and absence of frontal sinus (not obligatory). Despite the frequent presence of dental malocclusion in patients with maxillo-nasal dysplasia, very little is to be found in the otorhinolaryngologic literature. Traditionally, plastic surgeons have been more closely involved with the syndrome, presenting different methods of surgical correction to solve the aesthetic and/or functional problems.

\section{CASE REPORT}

A 4-year-old boy, diagnosed with acute leucosis, attended the pediatric department following referral from a ENT specialist. The mid-face profile was hypoplastic, the nose was flattened, the upper lip was convex with a broad philtrum, the nostrils were typically crescent in shape due to the short collumela, and a deep fold between the upper lip and the nose, resulting in an acute nasolabial angle. Mid-face hypoplasia was evident with an absence of fronto-nasal angle reflected in a straight profile. There was

\footnotetext{
Address for correspondence:

Plamen Kostov Nedev, 23, 9010 Varna, E. Georgiev str. B-10, BULGARIA

e-mail:drnedev@abv.bg
}

also reduced sagittal development of the nose. Transversally there was no apparent facial asymmetry. The lips were competent at rest. Intra-oral examination of the dentition revealed the presence of all permanent teeth apart from the third molars (fig. 1. fig. 2. and fig. 3.).

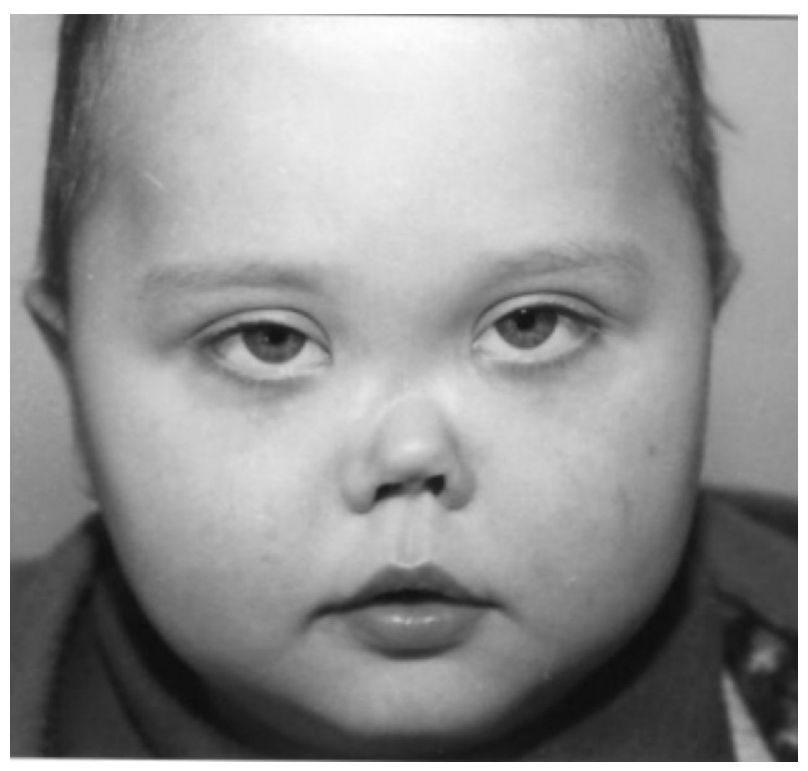

Fig. 1. A 4-year-old boy with maxillo-nasal dysplasia. Frontal view of the case

Nasal hypoplasia with reduced naso-frontal angle was identified with suspected mild hypertelorism. The flat dorsum and short septum of the nose, enlarged nasal angle, small naso-labial angle, maxillary micrognathism, and augmented upper lip, what makes the concave midface profile are the symptoms of Binder syndrome (maxillonasal displasia). There was a mild form of hypertelorism. Radio- 
graphic and CT exams report small anterior nasal spine, thin labial plate over incisor roots, nasomaxillary hypoplasia (absence of nasal bone and processus frontalis maxillae). No other structural abnormalities were seen.

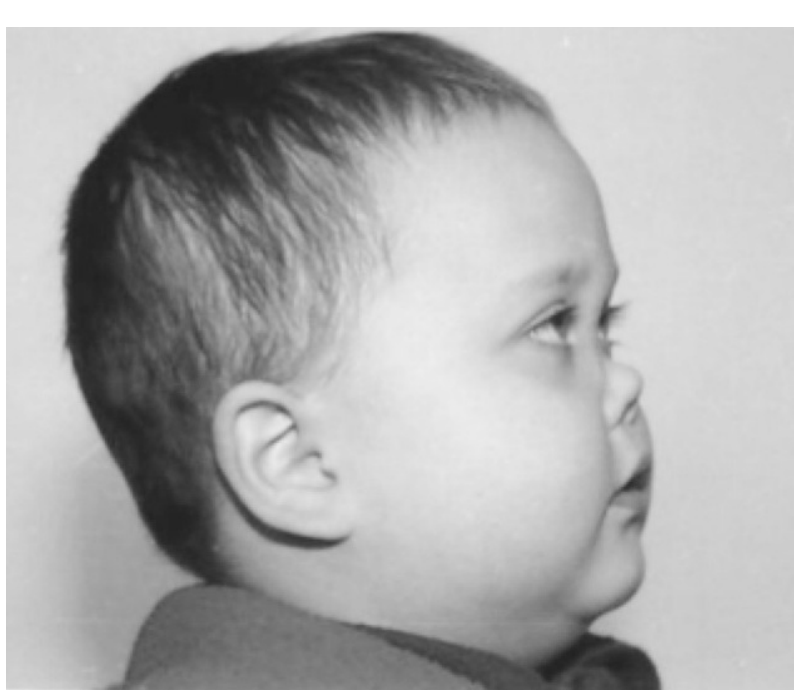

Fig. 2. Right profile view of the case

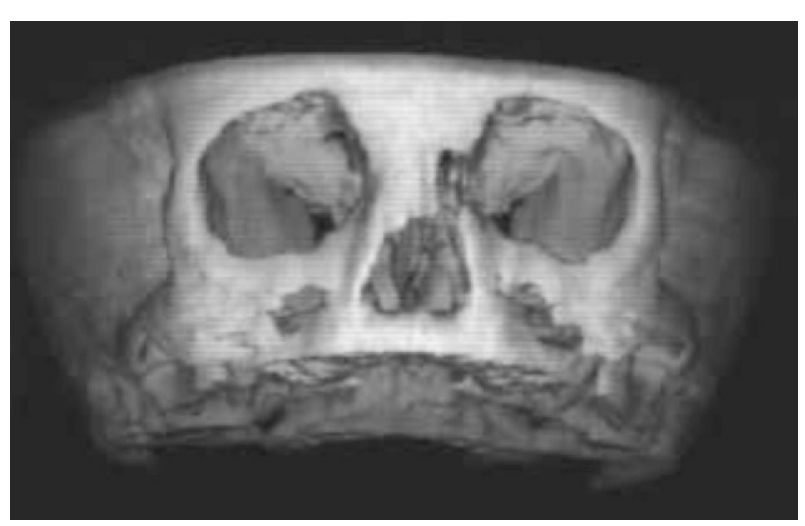

Fig. 3 A three-dimensional CT image - a small anterior nasal spine, nasomaxillary hypoplasia (absence of nasal bone and processus frontalis maxillae).

\section{DISCUSSION}

Many researchers suggest that Binder type maxillonasal dysplasia does not represent a distinct disease entity or syndrome, but, rather, is a nonspecific abnormality of the nasomaxillary regions. In most cases, the condition appears to occur randomly for unknown reasons (sporadically); rare familial cases have also been reported. The aetiology of this condition is connected with a disturbance of the prosencephalic induction centre during embryonic growth. (3) However, it has been suggested that there is a common concurrent induction process for both the prosencephalic area and the vertebrae, accounting for the increase of vertebral anomalies associated with the condition. (4) Birth trauma has also been suggested as a possible causative factor, but is not further substantiated in the literature.(5) The possibility of a family history was put forward by Ferguson and Thompson.(6) However, Olow-Nordenram and
Valentin were unable to disprove the possibility of a genetic aetiology in a study of 50 patients with the condition, involving 60 families.(7) In a further study of 97 individuals with Binder's syndrome, Olow-Nordenram (8) reported a positive family history was for 36 per cent. Gorlin et al. suggest that maxillo-nasal dysplasia is a non-specific abnormality of the nasomaxillary complex. They believed that familial examples are a result of complex genetic factors, similar to those involved in producing a malocclusion.(9) Nasal bone is formed in the third month of intrauterine life, from the centers of ossification (cells migrated from the neural crest) next to the cartilage of the nasal bone. In this complicated process, exogenous, genetic, and chromosomal factors all play a part. There is evidence that vitamin K-deficiency during human pregnancy can be caused by some chemicals as lithium, ethanol or the therapeutic use of warfarin or phenytoin. The pregnancy histories of three cases of Binder's syndrome are reported (10). One was associated with warfarin exposure, one with phenytoin exposure and one with alcohol abuse. It is proposed that Binder's syndrome can be caused by prenatal exposure to agents that cause vitamin K-deficiency (10). It is generally agreed that the lack of population frequency data has affected the evaluation of aetiological findings (5).

Individuals with Binder's syndrome have a characteristic appearance that is easily recognizable.The characteristic findings are a failure of development in the premaxillary area with associated deformities of the nasal skeleton and the overlying soft tissues. Affected individuals typically have an unusually flat, underdeveloped midface (midfacial hypoplasia), with an abnormally short nose and flat nasal bridge, underdeveloped upper jaw, relatively protruding lower jaw. The sense of smell is completely normal. Five per cent of affected individuals have been found to have hearing loss and 5\% nonspecific congenital heart defects(22). Maxillo-nasal dysplasia can also be combined with other malformations. For example, Olow-Nordenram and Radberg reported 44.2 per cent of a study sample to have malformation of cervical vertebrae $(7,8)$. The association with pseudo-mandibular prognathism has also been described $(1,11)$. In the most severe cases, the syndrome is associated with true mandibular prognathism, which requires combined orthodontic and surgical treatment (7). As the literature review shows maxillo-nasal dysplasia is often combined with different morbid conditions. Maxillonasal dysplasia is considered as a predisposing factor to frequent diseases of the upper airway tract. In our patient case the Binder syndrome is accompanied with acute leucosis.

As a syndrome maxillonasal dysostosis (defective ossification) is characterized by a short nose with a flat bridge, a short columella, an acute nasolabial angle, perialar flatness, a convex upper lip and a tendency to angle class III malocclusion (3). Since then there have been many reported cases of Binder syndrome, but no such diagnosis has been made antenatally. Binder syndrome, as it is seen in newborns, children or adolescents, is characterized by the naso-frontal angle being absent with the nose being hypoplastic with a small tip. The nostrils are usually half moon shaped and the 
upper lip is convex with a high arched palate. Mild hypertelorism is usually present as well as malocclusion and a lower overbite. There are various anomalies of the cervical spine which may be seen, such as separate odontoid process, spina bifida occulta, short posterior arch and block verterbrae (11). Strabismus and mild mental retardation have been occasionally described (12). The frontal sinuses are often hypoplastic or absent in $40-50 \%$ of cases (13). When maxillonasal dysplasia is observed at birth it is usually not thought to be important if it presents as a single finding. Individuals may also be seen as children or adolescents by orthodontists or plastic surgeons, and their facial features are then diagnosed as Binder syndrome (14). In 1866, Langdon Down described the phenolype of patients with trisomy 21 , indicating that they had "skin...deficient in elasticity, giving the appearance of being too large for the body... The face is flat and broad, and destitute of prominence.... and the nose is small". With that description Down laid the foundation for two ultrasonographic markers for this chromosomopathy: the nuchal translucency and the nasal bone. In 1966, Kisling (15) performed a radiological study on 68 adults with Down's syndrome and confirmed the absence of nasal bone in nine of them (12\%). Other authors supponed these findings. In 1994, Sandikcioglu (16) studied aborted fetuses with trisomy 21 and found radiological anomalies of nasal bone in $60 \%$ of those $(26 \%$ absent, 34\% hypoplastic). For many years, sonographers have known that the subjective impression of a "flat profile" can serve as an indicator of Down's syndrome, but only in 2001, a publication of Cicero et al. (17) revolutionized the world of the prenatal diagnosis: in 701 high-risk fetuses between 11 and 14 weeks of gestation, nasal bone was absent in three out of $603(0.5 \%)$ normal fetuses and 43 out of 59 $(73 \%)$ fetuses with trisomy 21 . A study of 5525 fetuses found absent nasal bone in 70\% of trisomy 21 fetuses compared with $0.5 \%$ of fetuses with normal genetic characteristics (19). In their latest assessment of the absent fetal nasal bone in a multiethnic population of 3788 , Cicero et al. (20) found an absent nasal bone in 161/242 (66.9\%) of trisomy 21 fetuses compared to $93 / 3358$ (2.3\%) of fetuses with normal chromosomes. The ultrasonographic examination of 7054 fetal profile Gamez 2005 (21) a nasal bone hypoplasia found in $1.8 \%$ of cases. Women aged 35 years or more in current prenatal care are considered high risk for Down syndrome pregnancy and are therefore routinely offered invasive tests (amniocentesis) in order to exclude chromosomal abnormalities. Nova days there are introduced noninvasive tests, using useful markers for fetal abnormalities, especially for chromosomal aberrations. (18)

\section{Treatment}

Surgical treatment can be limited only to reconstruction of the nasal dorsum and apex or additionally maxillary advancement. The management consists of nasal and maxillary correction followed by orthodontic rehabilitation. The treatment schedule in Binder syndrome depends on the progress of the symptoms in the face occlusion. Surgical treatment can be limited only to reconstruction of the nasal dorsum and apex or additionally maxillary advancement. Grafting to the osteo-chondral scafold of the nose can be carry out from 14-year-old, and osteotomy of the nose or maxilla should be planned after 18 -year-old. It is important to examine prenatal the facial features as they may well give an indication of an underlying severe fetal abnormality. However, the finding of a small flattened nose with no other abnormal features, in a fetus with a normal karyotype, is likely to carry a good prognosis with the possibility of satisfactory surgical correction (23).

We could conclude that the survey of the literature did not disprove the possibility of a genetic etiology, although it might not be the full explanation for the syndrome. The feature and degree of the abnormality depend on the time of exposition to harmful teratogenic factors. We recommend ultrasound screening and noninvasive genetic tests to look for congenital anomalies as well as assessment of gestational age. In conclusion, individuals with maxillonasal dysplasia shall be subjected to a treatment planning in collaboration between orthodontists and ENT surgeons.

\section{REFERENCES}

1. Noyes FB. Case report. Angle Orthod 1939; 9: 160-165

2. Binder KH. Dysostosis maxillo-nasalis, ein archinencephaler Missbildungskomplex. Deutsche Zahnarztuche Zeitschift 1962; 17: 438-44.

3. Holmstrom H. Kahnberg K. Surgical approach in severe cases of maxillonasal dysplasia (Binder's syndrome). Swedish Dental Journal 1988; 12: 3-10.

4. Olow-Norderam M, Radberg CT. Maxillonasal dysplasia (Binder syndrome) and associated malformations of the cervical spine. Acta Radiologica Diagnosis 1984; 25:353-360

5. Dyer F., Willmot D. R., Maxillo-nasal dysplasia, Binder's syndrome: review of the literature and case report. Journal of Orthodontics, 2002Vol. 29, No. 1, $15-21$

6. Ferguson JW, Thompson RPJ. Maxillonasal dysostosis (Binder syndrome) a review of the literature and case reports. Eur J Orthod 1985; 7: 145-148.

7. Olow-Nordenram M, Thilander B. The craniofacial morphology in persons with maxillonasal dysplasia (Binder syndrome). Am J Orthod Dentofac Orthop 1989; 95: 148-58.

8. Olow-Nordenram M, Valentin J. An etiologic study of maxillonasal dysplasia-Binder's syndrome. Scand J Dent Res 1987; 96: 69-74.

9. Gorlin R, Pindborg JJ, Cohen M Jr. Maxillonasal dysplasia (Binder syndrome). Syndromes of the head and neck. 1976 2nd Edition New York: McGraw-Hill

10. Howe AM; Webster WS; Lipson AH; Halliday JL; Sheffield LJ Binder's syndrome due to prenatal vitamin K deficiency: a theory of pathogenesis. Australian dental Journal. 1992 Dec; Vol. 37 (6), 453-60.

11. Demas PN, Braun TW. Simultaneous reconstuction of maxillary and nasal deformity in a patient with Binder's syndrome (Maxillonasal dysplasia). J Oral Maxillofac Surg, 1992; 50: 83-86. 
12. Winter RM, Baraitser M. Multiple congenital anomalies. In: A Diagnostic Compendium. London: Chapman \& Hall, 1991: 75 - 76

13. Horswell BB, Holmes AD, Barnett JS, Levant BA. Maxillonasal dysplasia (Binder's Syndrome): A critical review and case study. J Oral Maxillofac Surg 1987; 45: 114-122.

14. McCollum AG; Wolford LM ; Binder syndrome: literature review and long-term follow-up on two cases. The International Journal of Adult Orthodontics and Orthognathic Surgery. 1998; Vol. 13 (1), 45-58.

15. Kisiing E. Cranial morphology in Down's syndrome. Thesis, Munksgaard, Copenhagen; 1966.

16. Sandikcioglu M, Molsted K, Kjaer I. The prenatal development of the human nasal and vomeral bones. J Craniofac Genet Dev Biol 1994; 14: 124-34.

17. Cicero S, Curcio P, Papageorghiou A, et al. 2001. Absence of nasal bone in fetuses with trisomy 21 at 11-14 weeks of gestation: an observational study. The Lancet 358: 9294.

18. Sieroszewski P., Perenc M., Baoe-Budecka E., Suzin J. Ultrasound diagnostic schema for the determination of increased risk for chromosomal fetal aneuploidies in the first half of pregnancy Journal of Applied Genetics 2006, 47(2), 177-185

19. Zoppi MA, Ibba RM, Axiana C, Floris M, Manca F, Monni G, Absence of fetal nasal bone and aneuploidies at first-trimester nuchal translucency screening in unselected pregnancies, Prenat Diagn 2003; 23(6): 496-500

20. Cicero S, Longo D, Rembouskus G, Sacchini C, Nicolaides KH. Absent nasal bone at 11-14 weeks of gestation and chromosomal defects. Ultrasound Obstet Gynecol 2003; 22: 31-35.

21. Gamez F., Ferreiro P.: Fetal nasal bone as ultrasonographic marker for trisomy 21 in a low-risk population between 18 and 22 gestational weeks. The Ultrasound Review of Obstetrics and Gynecology, September 2005; 5(3): 171-177

22. Cook, K., Prefumo F., Presti F., Homfray T., and Campbell S. The prenatal diagnosis of Binder syndrome before 24 weeks of gestation: case report Ultrasound in Obstetrics and Gynecology Volume 16 Issue 6 Page 578-581. 